\title{
Impostor Phenomenon and Skills Confidence among Scholarly Communications Librarians in the United States
}

\section{Erin Elizabeth Owens}

\begin{abstract}
This survey-based study sought to measure the experience of impostor phenomenon among library personnel supporting scholarly communications in academic libraries in the United States. Additionally, the survey sought to assess confidence levels in key, professionally defined competencies and the factors most significantly affecting those confidence levels. Results indicated that, on average, scholarly communications librarians experience impostor phenomenon more frequently and intensely than academic librarians more broadly. The length of time spent working in libraries was negatively correlated with levels of impostor phenomenon, as were hours spent in specialized continuing education activities and number of research publications. Implications for improving training and mentoring opportunities to decrease impostor phenomenon are discussed.
\end{abstract}

\section{Introduction}

Academic librarians working in the area of scholarly communications routinely educate or assist faculty in regard to diverse issues of research data management, copyright, scholarly publishing, and research impact metrics. In many cases, these librarians are advising highly trained research scholars who have more experience with producing data and publishing scholarship. Although some of these librarians have tenure-track faculty status and their own resumes of publications, they hold master's degrees more often than PhDs, and others may be classified as staff; thus, librarians often find themselves perceived as less credentialed and capable by traditional teaching and research faculty. Librarians may feel they are "swerving out of their lane" in portraying themselves as expert consultants on complex topics of research scholarship. As would-be experts in this area, the profession expects librarians supporting scholarly communications to bring in or develop background knowledge, technical skills, outreach and instruction skills, and team building skills; their work may encompass some or all of the following areas of emphasis (sometimes in addition to other areas of librarianship as well):

- Institutional repositories (collecting and preserving content, repository solutions, metadata schemata, applying publisher policies, developing repository policies, and statistics);

Erin Elizabeth Owens is Professor, Access Services Coordinator \& Scholarly Communications Librarian in the Newton Gresham Library at Sam Houston State University; email: eowens@shsu.edu. (C2021 Erin Elizabeth Owens, Attribution-NonCommercial (https://creativecommons.org/licenses/by-nc/4.0/) CC BY-NC. 
- Publishing (platforms, the publishing lifecycle, persistent identifiers, metadata schemata, technical support, system administration, and metrics);

- Copyright (law, the judicial environment, author's rights, orphan works, licensing, permissions requests, and campus policies);

- Data management (planning, description and storage, applying funder mandates, repository solutions, collecting and accessing data sets);

- Assessment and impact metrics (indicators and their strengths and weaknesses, emerging alternative measures of impact or "altmetrics," faculty profile systems, evaluation of journals).

Speaking of altmetrics in particular, Robin Chin Roemer noted that there exists a "hesitation to position oneself as an expert in the area when engaging with stakeholders, including researchers, vendors, and other librarians." ${ }^{1}$ One could assume that a similar hesitation exists in other aspects of scholarly communications competencies as well, when librarians are supporting highly experienced researchers and prolific writers. Furthermore, the specialty changes rapidly as new technologies and metrics emerge, copyright laws and interpretations evolve, and researcher and publisher behaviors change; on top of that, the field addresses many questions without clearly defined answers. A librarian sometimes questioning their expertise in this broad, challenging, and rapidly changing field would be understandable.

The psychological concept of impostor phenomenon is defined as "an internal experience of intellectual phoniness" in which, "despite outstanding academic and professional accomplishments," a person "persist[s] in believing that they are really not bright and have fooled anyone who thinks otherwise." 2 Impostor phenomenon may be a useful lens through which to evaluate librarians' confidence in taking on roles of leadership and expertise in scholarly communications topics and to propose mechanisms to improve job confidence. This study seeks to measure to what extent impostor phenomenon is experienced by scholarly communications librarians; in what aspects of their work they particularly lack confidence in their expertise; and what factors may affect their confidence level. Potential interventions to address feelings of impostor phenomenon and lack of confidence are then considered.

\section{Literature Review}

Impostor phenomenon was first defined in 1978 by psychologist Dr. Pauline Rose Clance. ${ }^{3}$ This experience is sometimes also termed impostor syndrome, impostor experience, or impostorism, and impostor is sometimes instead spelled imposter. This paper will prefer the originally coined term impostor phenomenon, in keeping with the requests of Dr. Clance and the official spelling of her term.

Standardized instruments for measuring impostor phenomenon first appeared in 1981, with the Harvey Impostor Phenomenon Scale (HIPS). In 1985, the Clance Impostor Phenomenon Scale (CIPS) appeared. The Perceived Fraudulence Scale (PFS) provided another alternative in 1991, and the Leary Impostorism Scale (LIS) emerged in 2000. More recently, the State Impostor Phenomenon Scale (SIPS) was proposed in 2010.

As Kets de Vries observes, impostor phenomenon (IP) "is highly prevalent in academia and medicine, both disciplines in which the appearance of intelligence is vital to success."4 Hutchins and Rainbolt studied the triggers and coping mechanisms for IP among academic faculty, finding that triggering incidents were most often related to questioning expertise; scholarly productivity; comparisons to colleagues; and successes (that is, promotions, awards, or other accomplishments that caused feelings of self-doubt or insufficiency). ${ }^{5}$ Parkman pro- 
vides additional review of the literature focused on IP in higher education generally. ${ }^{6}$ Hutchins, Penney, and Sublett recommend active coping approaches such as training, coaching, and mentoring for addressing the experience of IP. ${ }^{7}$

Within the literature of professional librarianship, several authors have shared their personal experiences with IP; these personal anecdotes are informative, but they do not contribute to empirical evidence regarding the prevalence or causes of the problem. ${ }^{8}$ Other work within the library science discipline has focused on acknowledging, rather than measuring, the problem and recommending possible coping techniques and interventions, such as mentoring and education. ${ }^{9}$ In particular, Farrell, Alabi, Whaley, and Jenda focused on the value of mentorship in combatting impostor phenomenon, while Rakestraw recommends education, mentoring, and time, along with therapy if warranted, as tools for managing IP. ${ }^{10}$ Most recently, Barr-Walker, Werner, Kellermeyer, and Bass analyzed coping strategies among health sciences librarians, and found that, although the use of any strategy was better than none, "external coping strategies that drew on the help of another person or resource, such as education, support from colleagues, and mentorship" were generally more effective than "internal strategies like reflection, mindfulness, and recording praise."11

The first empirical study of IP among college and research librarians was conducted by Clark, Vardeman, and Barba using the Harvey Impostor Phenomenon Scale (HIPS); in their findings, approximately one in eight academic librarians reported above average IP scores. They found that race, gender, and employment classification were not associated with differences in IP scores, but younger and less experienced librarians reported higher rates of IP. ${ }^{12}$ Martinez and Forrey similarly evaluated IP among librarians, though their study emphasized qualitative open-ended questions rather than quantitative Likert scales; they included public and special libraries as well as academic (though academic librarians nevertheless made up 90 percent of their respondents), and 85 percent of their participants reported having felt insecure or underqualified on at least one occasion in their careers. ${ }^{13}$

Bortmas surveyed "technical" librarians, within the Code4Lib, LITA, and ALCTS listserv membership, to assess impostor phenomenon among this specialized population of librarians. ${ }^{14}$ This study used the Clance IP Scale and the Perfectionist Self Presenting Scale (PSPS); Bortmas found that just shy of 67 percent of participants experienced Frequent IP (61-80 points); percentage of participants scoring at other levels on the Clance IP Scale are not specified. The experience was less frequent among librarians with more years of experience, as well as brand-new librarians with less than three years of experience.

In 2019, Barr-Walker, Bass, Werner, and Kellermeyer replicated Clark's 2014 methods, using the HIPS questionnaire to assess IP among librarians specializing in the health sciences. ${ }^{15}$ They found that one in seven health sciences librarians experienced feelings of IP, similar to Clark's findings on the rate among academic librarians more generally, but experiences were lower among those individuals who had an educational background in the health sciences.

As of yet, no studies have looked at the experience of IP among librarians specializing in scholarly communications. The present study seeks to fill that gap by gauging whether this group experiences IP at greater, lesser, or equivalent rates compared to academic librarians in general; what factors may impact confidence in professional knowledge; and whether variables such as increased training in the specialization or greater personal experience in scholarly publishing correlate to lower rates of impostor phenomenon. By increasing our understanding 
of the prevalence of IP and factors negatively affecting the professional confidence of scholarly communications librarians, appropriate interventions, such as hands-on training materials or mentoring programs, can be proposed.

\section{Methodology}

This study employed an online survey to ask librarians engaged in scholarly communications work about their experience of impostor phenomenon; their confidence in their knowledge of the topics identified in the NASIG Core Competencies for Scholarly Communications Librarians; ${ }^{16}$ and factors they see as contributing to their lack in confidence. The confidence questions and demographic questions were developed by the author, employing the NASIG Core Competencies as a suitably granular way to measure areas of strength and weakness. Other tools that were considered but rejected as models for defining areas of confidence included:

- ACRL Scholarly Communications Toolkit, in which the topics were deemed not granular enough for this purpose, ${ }^{17}$

- LIS-Bibliometrics Competency Model for bibliometric work, and Librarians' Competencies Profile for Research Data Management, which were both too focused on only select aspects of scholarly communications work, ${ }^{18}$

- Librarians' Competencies Profile for Scholarly Communication and Open Access, which shared significant overlap with NASIG Core Competencies but excluded research data management; ${ }^{19}$

- Jisc's summary of Scholarly Communications Competencies, which also provided the desired level of granularity but was not as formalized or stable a document as the NASIG Core Competencies. ${ }^{20}$

The impostor phenomenon questions were used, with permission, from the Clance Impostor Phenomenon Scale (CIPS) ${ }^{21}$ Five instruments were originally considered for measuring IP: the Harvey Impostor Phenomenon Scale (HIPS, 1981); the Clance Impostor Phenomenon Scale (CIPS, 1985); the Perceived Fraudulence Scale (PFS, 1991); the Leary Impostorism Scale (LIS, 2000); and the State Impostor Phenomenon Scale (SIPS, 2010). ${ }^{22} \mathrm{Al}-$ though HIPS is the longest-lived instrument and CIPS the most frequently used instrument, neither has conclusively been established as a gold standard for evaluating IP. However, far less evaluation is available for the newer tools, and they have not necessarily been proven to be more reliable instruments. The author consulted validations, reviews, comparisons, and systematic reviews of these instruments to determine the most appropriate instrument to adopt in this context. ${ }^{23}$

The PFS was eliminated from consideration primarily because of its length: with 51 items in addition to the additional desired questions regarding confidence and demographics, the author was concerned that the time required by the survey would be significant, and the corresponding completion rate would be very low. The LIS, on the other hand, was eliminated due to its extreme concision-only 7 statements - along with a scarcity of instrument evaluation: the LIS is not even referenced in the APA Dictionary of Psychology entry on impostor phenomenon, which mentions the HIPS, CIPS, and PFS. ${ }^{24}$ SIPS, too, was eliminated due to a lack of validation and studies employing the instrument, probably due to its relative newness. In the end, the author preferred the Clance IP Scale (CIPS) over the HIPS and obtained the permission of its creator, Dr. Clance, to reuse it in this study. 
After the survey instrument and overall methodology were approved by the Institutional Review Board (IRB) at the author's institution, the survey was distributed widely through both strategic and convenience recruiting strategies. First, using the website for the Carnegie Classification of Institutions of Higher Education, ${ }^{25}$ a list was downloaded of universities classified at the master's and doctoral levels. The websites of those universities' libraries were searched to identify librarians with job titles related to scholarly communication, ${ }^{26}$ and survey invitations were emailed directly to these individuals as a form of strategic recruitment. Second, convenience recruiting was achieved by distributing a general survey invitation to a selection of relevant professional listservs. ${ }^{27}$

The survey was available from February 12 to March 31, 2020, on the Qualtrics survey platform (hosted by the author's university). Settings were employed to anonymize responses so that all identifying information, including computer IP addresses, was omitted from the data recording. Because of these anonymizing settings, no mechanism existed to prevent multiple responses from an individual. Following the survey, participants had an opportunity to enter a drawing for a $\$ 25$ Amazon gift card, but these optional drawing entries were submitted and stored separately from survey responses, so a respondent's contact information could not be traced back to their responses. The survey instrument is openly available online at https://shsu-ir.tdl.org/handle/20.500.11875/2866. Analysis on the data was then conducted using Microsoft Excel and IBM SPSS.

\section{Results}

\section{Demographics}

A total of 206 participants accessed and began the survey. Of those who fully completed the survey, 21 were deemed ineligible because they were not presently employed in an academic library within the United States, or because they rarely or never supported scholarly communications in their library. A total of 149 survey responses were complete and eligible for analysis; it is difficult to say whether this is a representative sample since it is not known how many librarians in the United States are practicing in roles related to scholarly communications.

Of these, 61.1 percent reported that scholarly communications was their primary role, while the other 38.9 percent indicated that scholarly communications was an important secondary responsibility in their position. More than one-third $(36.9 \%)$ of respondents reported spending 76 to 100 percent of their work hours in the 2019 calendar year in duties related to supporting scholarly communications, while another 16.1 percent reported spending 51 to 75 percent of their work hours on these duties; this yields a total of 53 percent of respondents who devote more than half their time to specializing in scholarly communications. Another 20.1 percent commit 26 to 50 percent of their work hours to these duties, and the last 26.8 percent spend only 0 to 25 percent of their time in a scholarly communications capacity.

In terms of institutional demographics, 69.8 percent of respondents worked at public universities, while 30.2 percent worked at private universities. About half of the responses (50.3\%) came from respondents at institutions with a Carnegie Classification of R1: Doctoral Universities - Very high research activity. The R2 classification, Doctoral Universities - High research activity accounted for another 17.5 percent of responses. The remaining respondents were distributed across the other classifications (see figure 1). 


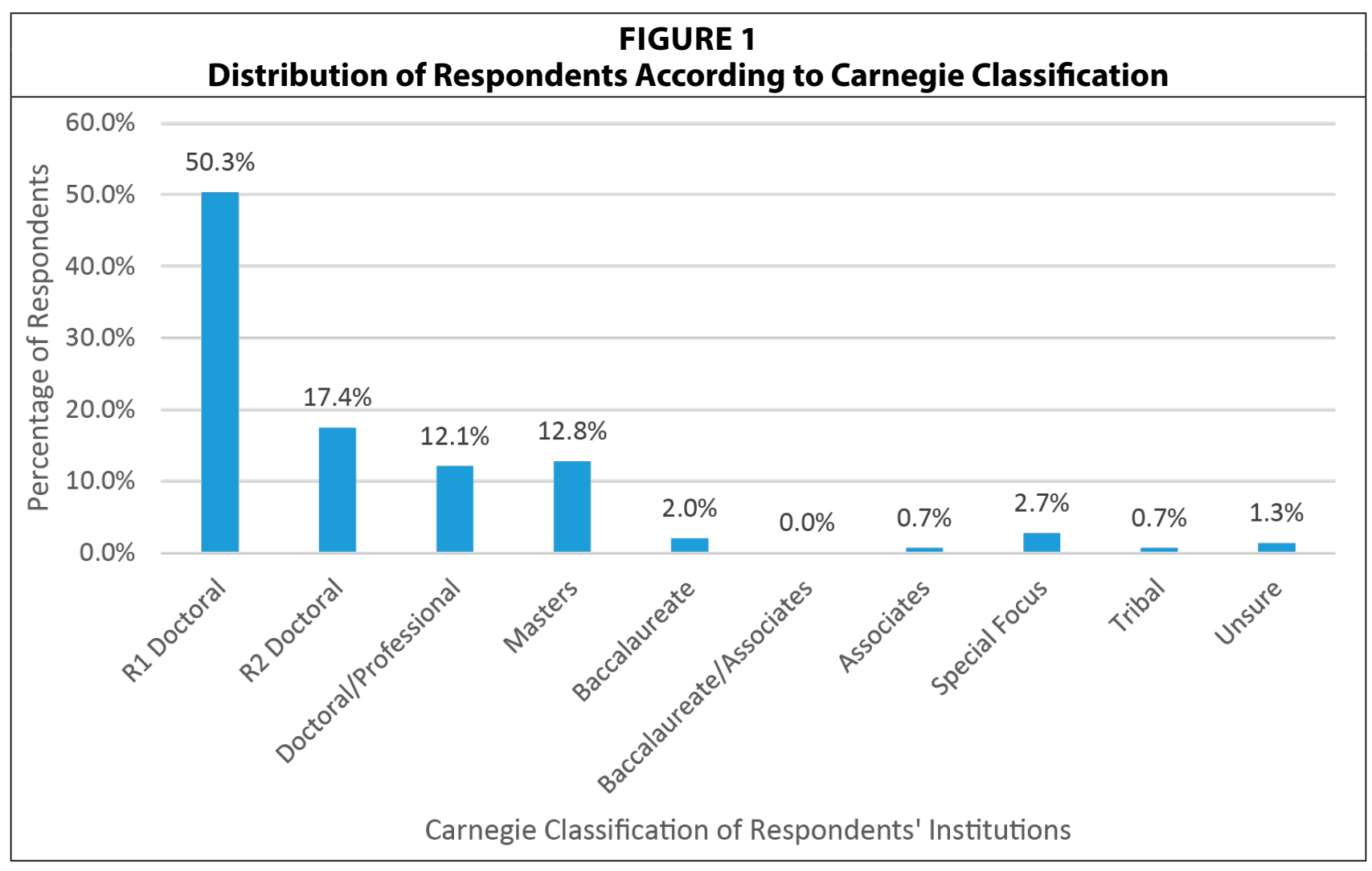

Respondents were split almost in half between those in tenured/tenure-track faculty positions (or equivalent terminology; $48.3 \%$ ) and those in nontenure-track positions (51.7\%). Among the 72 respondents on tenure tracks (or the equivalent terminology), 55.6 percent had achieved that milestone, while 43.1 percent had not yet reached tenure. One respondent $(1.4 \%)$ preferred not to indicate their tenure status.

Survey respondents skewed toward female (71.8\%) as opposed to male (21.5\%), nonbinary/ third gender $(2.7 \%)$, self-described $(0.0 \%)$, and those who preferred not to share their gender (4.0\%). Participants also skewed toward those who did not personally identify as persons of color (non-POC; $84.6 \%$ ), versus just 11.4 percent who did self-identify as POC and 4.0 percent who preferred not to say.

In terms of education, 17.5 percent of respondents were first-generation college graduates at the undergraduate level; 23.5 percent were the first in their families to receive graduate degrees; and the majority (57.7\%) did not identify as a first-generation college graduate. (Another 1.3 percent declined to state their first-generation status.) Most respondents held an ALA-accredited master of library science (MLS) or equivalent degree (93.3\%), though a few did not hold an MLS (6.7\%).

A little more than half of respondents (53\%) had been in libraries for more than 10 years, while the other 47 percent had less than 10 years' experience in libraries (see figure 3). However, experience significantly skewed the other direction in terms of years spent working specifically with scholarly communications in libraries: 87.2 percent of respondents had been working in this specialization for less than 10 years, while only 12.8 percent had accrued more than 10 years' experience (see figure 2).

Respondents were also asked about their experience publishing academic research in the form of peer-reviewed journal articles, book chapters, or books, whether single-authored or 


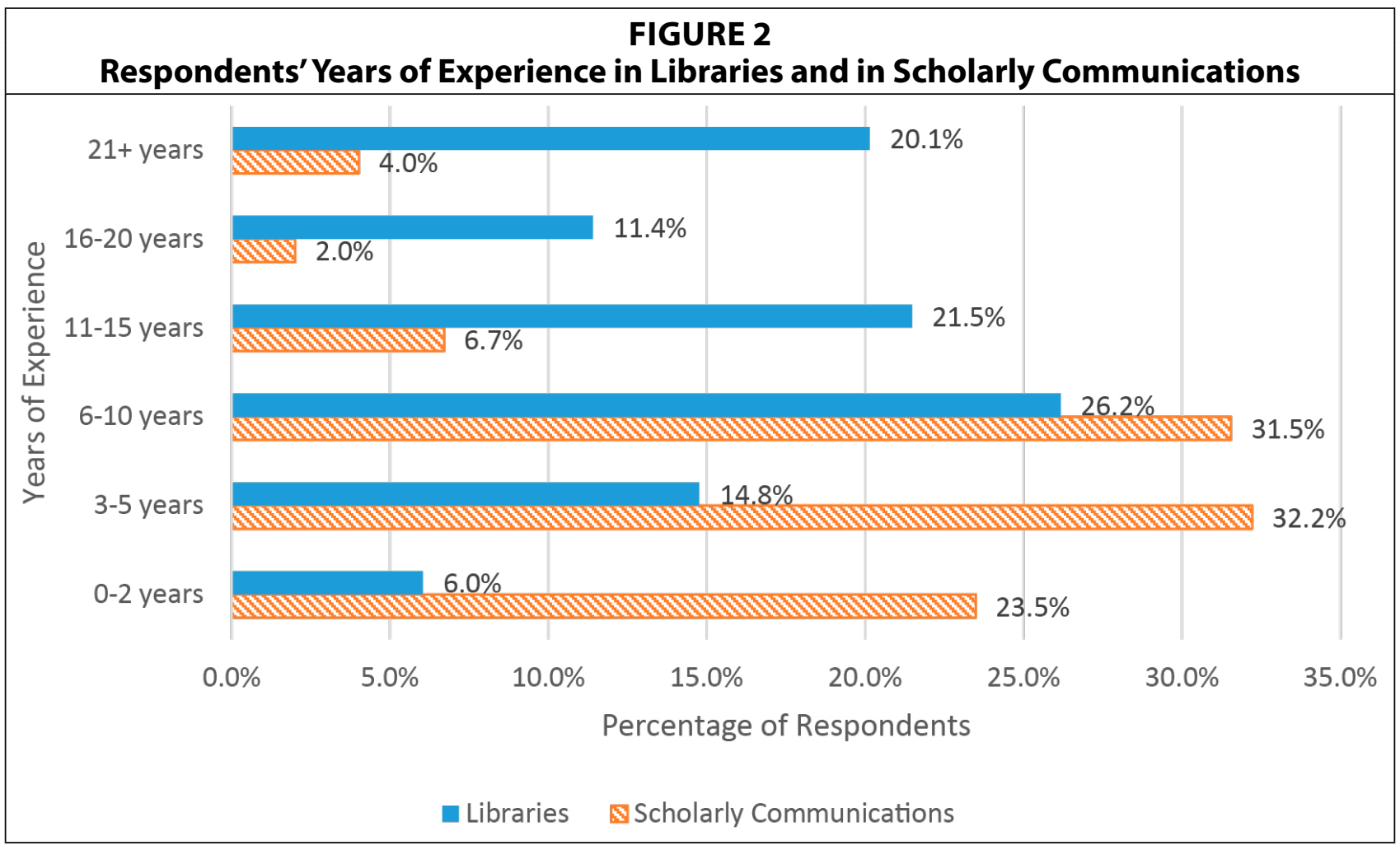

co-authored. Quantity of publications ranged from $0(18.8 \%)$ to $65(0.7 \%$, or one participant). The largest group of respondents $(43.0 \%$ ) had published between 3 and 10 items (see figure 3 ).

Finally, respondents were asked how many hours of continuing education or professional development related to scholarly communications they accrued during the 2019 calendar year. Individual answers ranged from 0 to 600 hours, with the majority (53.0\%) of respondents reporting 0 to 20 hours (see figure 4 ).

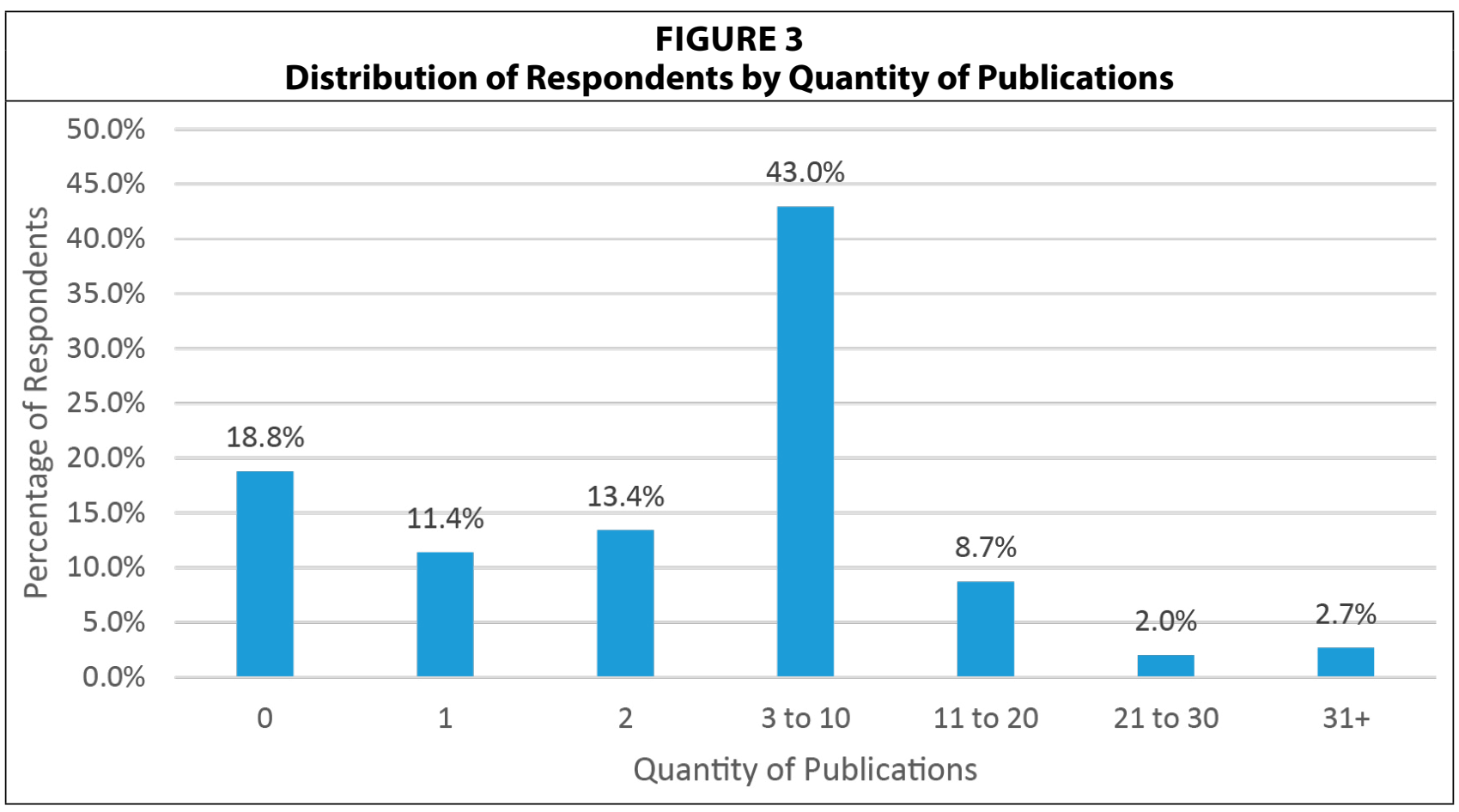




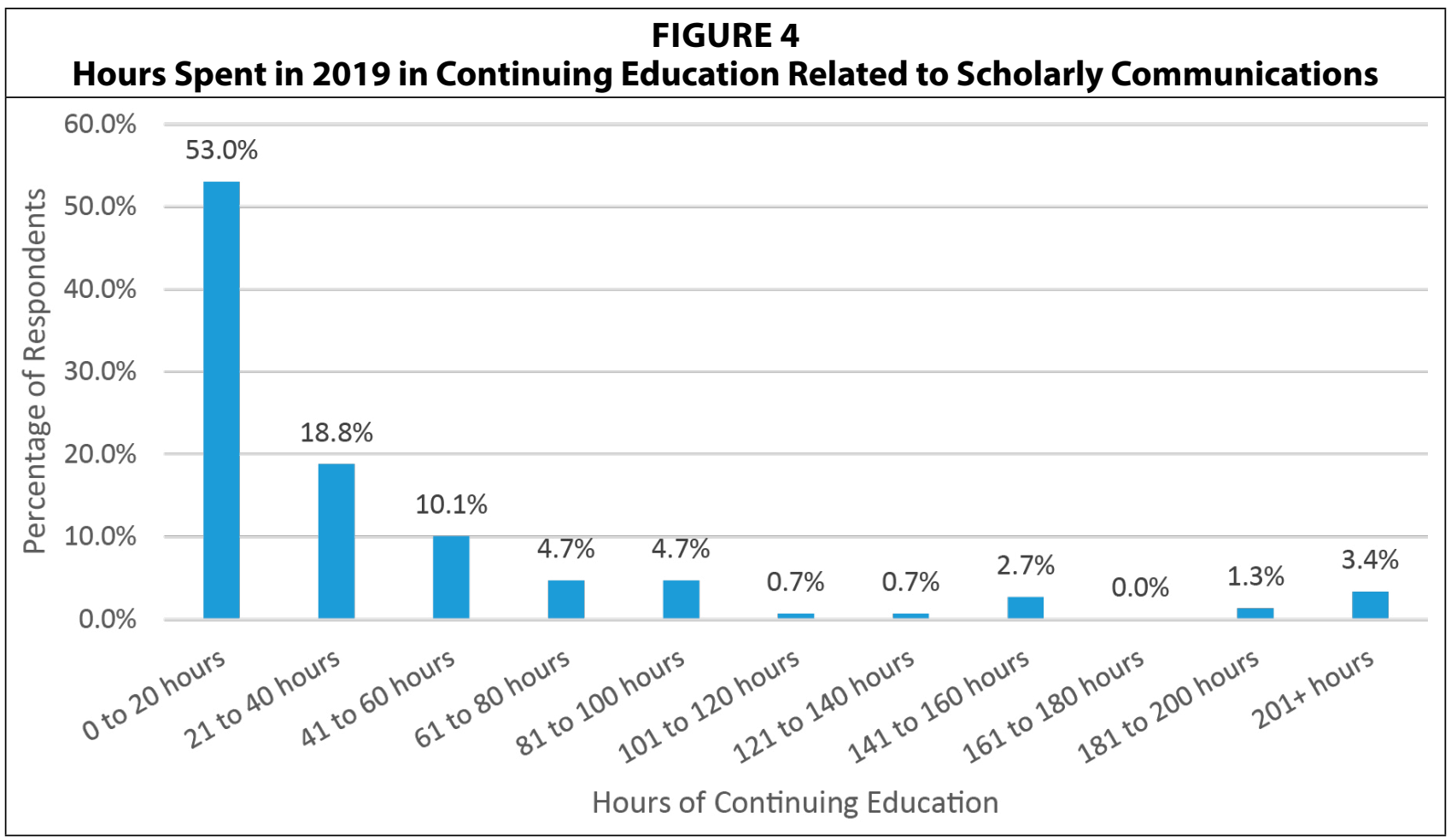

\section{CIPS Scores}

The instructions for scoring the Clance Impostor Phenomenon Scale (CIPS) group scores into four ranges: 40 points or less, Few Impostor Characteristics; 41-60 points, Moderate IP Experiences; 61-80 points, Frequent Impostor Characteristics; and more than 80 points, Intense IP Experiences. Respondents' answers were totaled and divided into these ranges according to the CIPS scoring instructions; as the instructions explain, "The higher the score, the more frequently and seriously the Impostor Phenomenon interferes in a person's life." ${ }^{28}$ The resulting distribution of scores resembled a fairly classic bell curve, with a slight skew toward greater experience of impostor phenomenon, as depicted in figure 5. The average CIPS score in this study was 61.6, which just barely crosses the threshold from Moderate to Frequent experience of IP. The

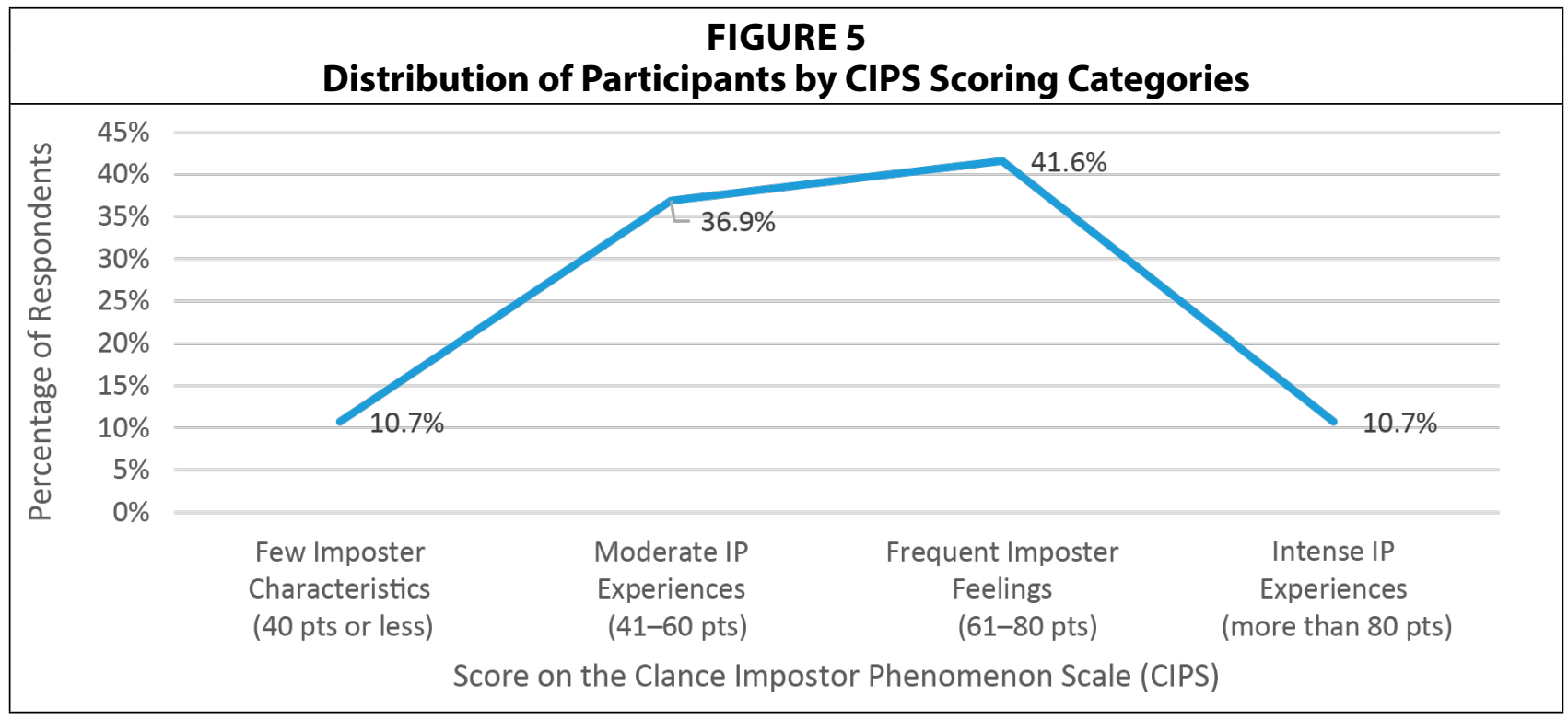


median score was 62, and the mode was 43. Both extreme ends of the spectrum - Few Impostor Characteristics and Intense IP Experiences - included 10.7 percent of respondents. The majority of participants (78.5\%) fell under the bell curve, with 36.9 percent scoring Moderate IP Experiences, and the remaining 41.6 percent scoring Frequent Impostor Characteristics.

\section{NASIG Core Competencies Confidence Levels}

Participants rated their own confidence in different areas identified by the NASIG Core Competencies for Scholarly Communications Librarians. The NASIG document describes five areas of emphasis, namely, Institutional Repository Management, Publishing Services, Copyright Services, Data Management Services, and Assessment \& Impact Metrics. Confidence was reported on a 5-point Likert scale ranging from 1 (no confidence at all) to 5 (a great deal of confidence). Some professional positions do not expect a librarian to practice in all of these areas, so participants had the option to mark individual competencies as Not applicable or not part of my job description. The supplemental materials include detailed graphs for all areas of emphasis, if they are not presented here in the narrative (https://shsu-ir.tdl. org/handle/20.500.11875/2866).

In the first area of emphasis, Institutional Repository Management, NASIG identifies six key competencies. Among these, respondents indicated the highest confidence in Knowledge of and ability to apply publisher policies on archiving: 33.6 percent indicated a great deal of confidence. The lowest level of confidence was in Knowledge of and ability to apply metadata schemata, for which 28.8 percent of respondents indicated little or no confidence. The competencies of 1) Collecting, storing, and preserving faculty, staff, and student intellectual output and 2) Knowledge of and ability to apply metadata schema were the most likely to be outside the scope of respondents' job descriptions, though still at relatively low rates (16.8\% and $15.4 \%$ respectively).

In the second area, Publishing Services, NASIG identifies seven competencies. Only in one of these, Knowledge of and experience with the full life cycle of publishing, did more than 20 percent of respondents indicate a great deal of confidence. On the other hand, five competencies in this area saw more than 20 percent of participants with only a little confidence; when little and no confidence responses were combined, two of those increase past 30 percent, and two others soar past 40 percent. The competency most likely to fall outside the scope of job descriptions, at 24.8 percent, was Perform system administration and programming.

Seven competencies make up the area of Copyright Services. Understanding of authors' rights was an area of high confidence, with 38.9 percent of participants indicating a great deal of confidence in that competency; in fact, zero participants indicated no confidence at all in this competency, as well as in Knowledge of pertinent national copyright law. However, Awareness of the judicial environment had the largest rate of both no confidence (8.1\%) and a little confidence $(25.5 \%)$. The competency least in scope of participant positions (16.8\%) was Performing license services.

Data Management Services, which included six competencies, saw generally lower confidence across the board: all competencies achieved 10.1 percent or fewer respondents reporting a great deal of confidence, with the highest response to Knowledge of and experience with open source and hosted data repository solutions and Knowledge of and ability to apply funder mandates related to data storage, access, and retention. The majority of respondents reported a moderate or little amount of confidence in all six competencies. Knowledge of text and data mining received the greatest response $(16.8 \%)$ for respondents with no confidence at all, followed by Collec- 
tion development, organization of, and access to third party data sets (12.1\%), which was also the competency most reported as outside the scope of job duties $(18.8 \%)$. Figure 6 illustrates the confidence levels in Data Management.

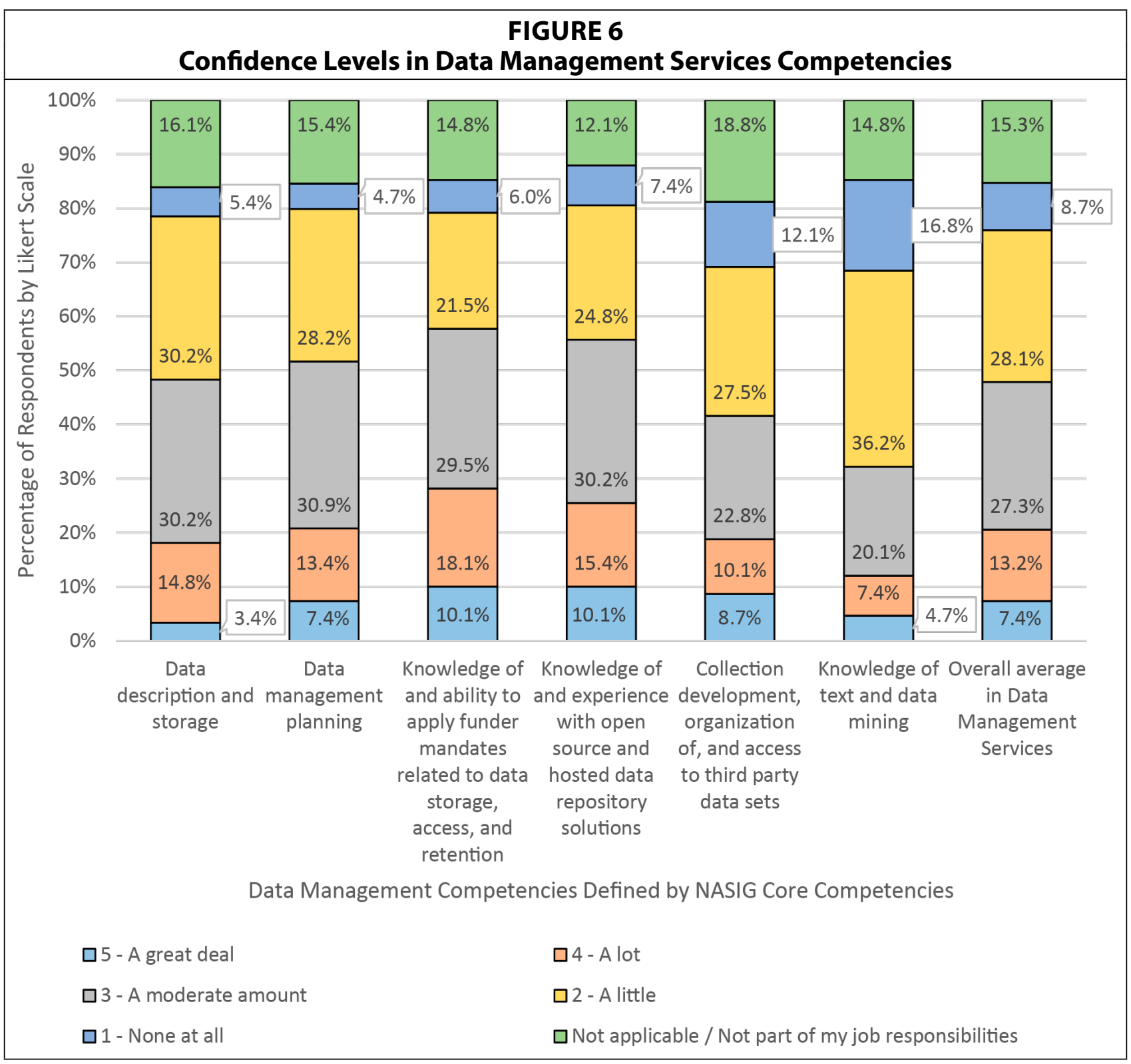

In the area of Assessment and Impact Metrics, five competencies were included. Respondents felt a great deal of confidence in Evaluation of journals (open access and traditional), at 35.6 percent, and all competencies saw very low rates of no confidence at all. This area of emphasis also appeared the most likely to be included in all job descriptions, as no competency rated more than 7.4 percent of respondents saying it was outside their duties.

Although respondents showed variable levels of confidence in the technical skills areas, they reported significantly and consistently greater confidence in their possession of the Key Strengths defined by NASIG (see figure 7). All strengths saw more than 37 percent of participants reporting a great deal of confidence, with Communication skills (oral and written) 


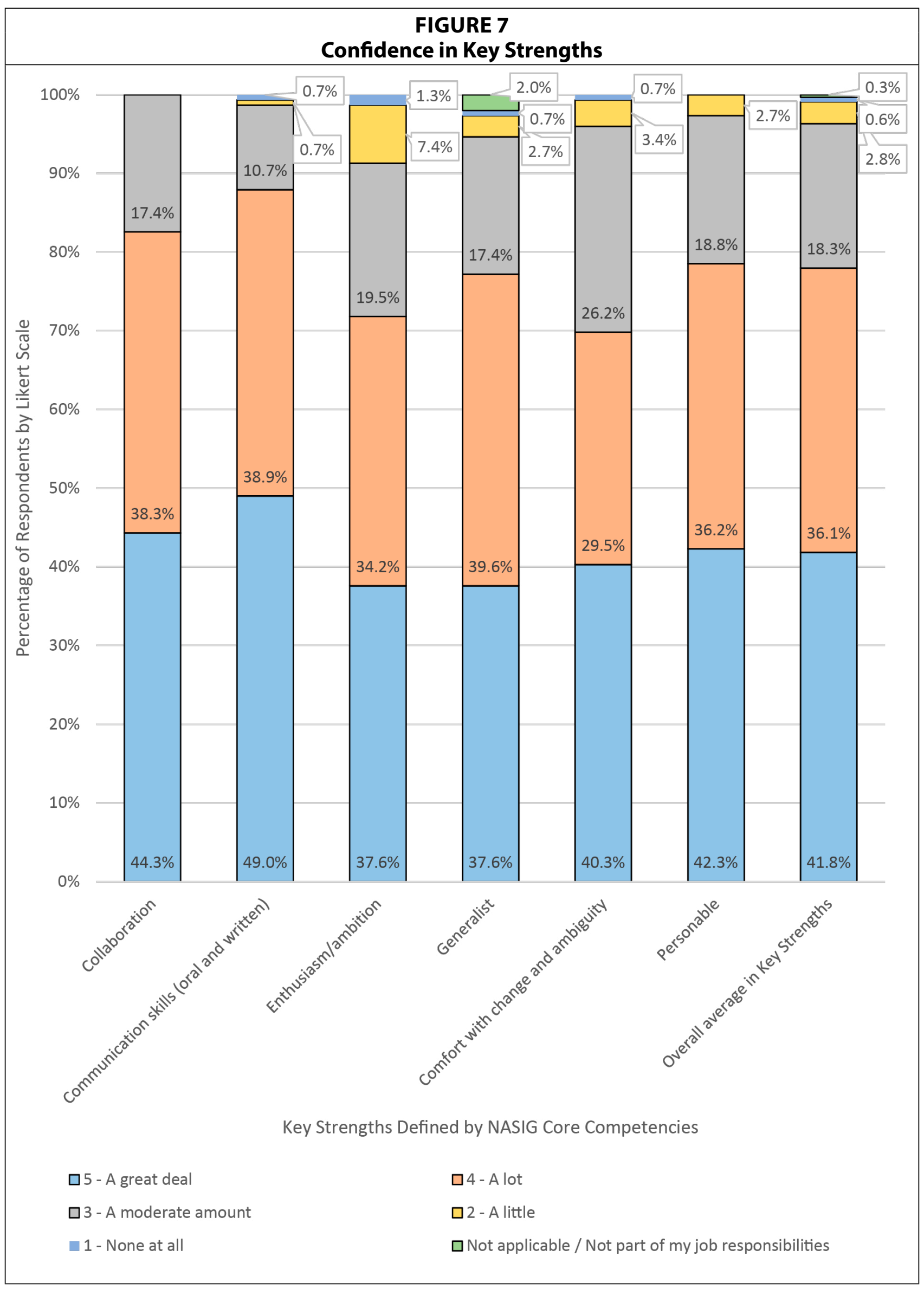


rating the most confidence at 49 percent. When a great deal of confidence and a lot of confidence were combined, this jumped to 87.9 percent of respondents showing high confidence in their communication. Meanwhile, 82.6 percent had a great deal or a lot of confidence in their collaboration skills, and 78.5 percent felt a great deal or a lot of confidence about being personable. Fewer than 1.5 percent of respondents reported no confidence at all in any key strength; these numbers ranged from 0.7 to 1.3 percent. Only Generalist received any reports of the strength being outside the scope of a participant's job description $(2.0 \%)$.

\section{Factors Affecting Confidence}

Users who indicated Moderate, Little, or No confidence on any competencies in an area were then asked to consider factors affecting their confidence level. Users could select multiple suggested factors and could also write in other influences. For the convenience of reporting, the full-sentence factors that were suggested to survey participants have been assigned short descriptive names (see table 1).

\begin{tabular}{|l|l|}
\hline \multicolumn{2}{|c|}{ Short Names Assigned to Factors Impacting Confidence } \\
\hline Short Name for Reporting & Full Response Seen and Selected by Respondents \\
\hline Need More Time and Experience & $\begin{array}{l}\text { I am still new to working with the topic(s) and need more time/ } \\
\text { experience. }\end{array}$ \\
\hline Too Many Responsibilities & $\begin{array}{l}\text { I have too many responsibilities and have not been able to devote } \\
\text { enough time to the topic(s). }\end{array}$ \\
\hline Lack of Training Completed & I have not completed enough training on the topic(s). \\
\hline Lack of Training Found & I have not found enough training available on the topic(s). \\
\hline Lack of Hands-on Training & $\begin{array}{l}\text { Although conceptual training is available for the topic(s), I need } \\
\text { practical / hands-on training that I have been unable to find. }\end{array}$ \\
\hline Lack of Practice and Demand & $\begin{array}{l}\text { I have insufficient practice with the topic(s) due to lack of user } \\
\text { demand in my environment. }\end{array}$ \\
\hline I Feel Like I Don't Get It & $\begin{array}{l}\text { I have an insufficient personal understanding of the key concepts of } \\
\text { the topic(s); I feel like I "don't get it." }\end{array}$ \\
\hline Rapid Change & $\begin{array}{l}\text { The information, standards, and/or practices in the topic(s) change } \\
\text { too rapidly to keep up. }\end{array}$ \\
\hline Inappropriate User Demands & $\begin{array}{l}\text { The requests/demands of my users or university administrators } \\
\text { do not fit with our profession's recommended best practices (for } \\
\text { example, wanting to use impact metrics in inappropriate ways). }\end{array}$ \\
\hline
\end{tabular}

Across all five areas of emphasis, one factor was most cited as negatively impacting respondents' confidence levels: Too Many Responsibilities. This made up nearly one-quarter (24.0\%) of all factors selected for all areas of competency. High impact was also attributed to three other factors: Need More Time and Experience (18.4\%); Lack of Training Completed (18.3\%); and Lack of Practice and Demand (17.6\%). All other factors averaged below 8 percent (see figure 8).

When each area of emphasis was evaluated individually, instead of in aggregate, a few other observations surfaced. Data Management Services saw a higher rate of respondents selecting Lack of Hands-On Training (9.4\%), and Rapid Change had a greater impact on confidence in Copyright Services than in other areas $(7.4 \%)$-although these admittedly represent 


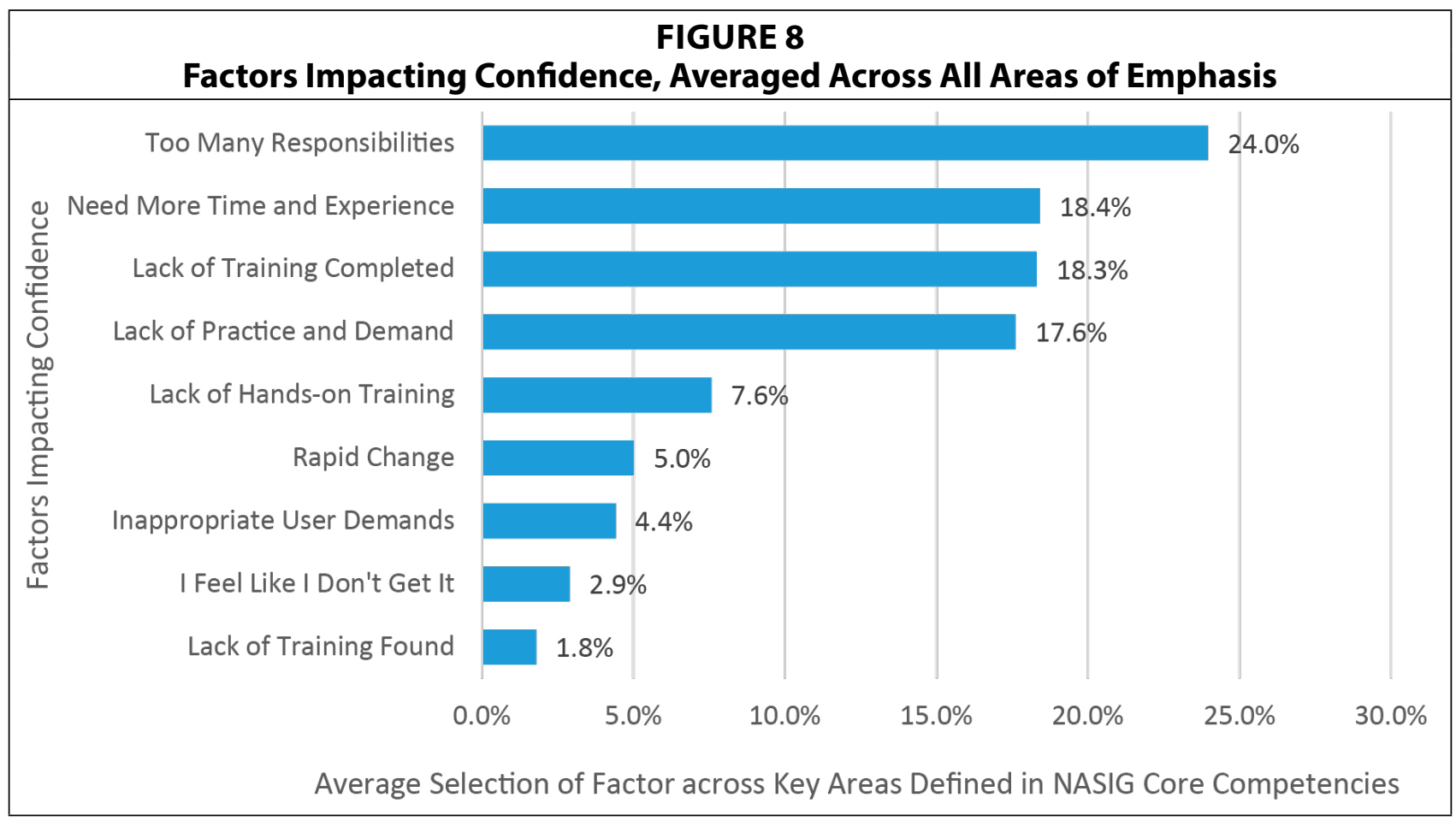

small percentages of the overall population, they still represent differences of greater than one standard deviation from the mean. Additional factors written in by participants included lack of funding for training; management of publishing services or institutional repositories by a consortium, which centrally handles more of the technical aspects; and the belief that "a lot of the concepts around metrics are bulls**t so I ignore them."

\section{Relationships between CIPS Scores and Other Variables}

When the relationships between CIPS score and other variables were evaluated statistically, mean CIPS scores differed significantly between librarians grouped by years of experience. Specifically, those with 3-5 years of experience in libraries had significantly higher CIPS scores than those with $21+$ years of experience in libraries. The sample of librarians with $0-2$ years of experience was very small compared to the other groups; with a larger number of respondents in that group, a significant difference might also have appeared between 0-2 years and 21+ years. No other differences by years of experience were statistically significant.

Although years of experience in libraries was meaningful, years of experience specifically in scholarly communications revealed no statistically significant difference in mean CIPS scores. Additionally, statistical tests did not find significant differences between groups based on gender, first-generation college status, Carnegie classification of the participant's employing institution, or tenure eligibility and status. Significant differences also did not manifest between people of color (POC) and non-POC; library personnel holding an MLS or equivalent degree and non-MLS personnel; or librarians working at publicly controlled versus privately controlled educational institutions.

A small but statistically significant negative correlation existed between CIPS score and number of publications, as well as a small negative correlation between CIPS score and hours of continuing education in scholarly communications. According to these negative correlations, as publications or hours of continuing education increase, CIPS scores tend to decrease. 
No significant correlation existed between CIPS score and percentage of work hours spent in scholarly communications. For readers interested in more detail, the supplemental materials include more details of the statistical tests conducted and their associated $p$-values (https:// shsu-ir.tdl.org/handle/20.500.11875/2866).

\section{Relationships between CIPS Scores and NASIG Core Competencies Confidence Levels}

Comparing NASIG Core Competencies confidence levels between the highest and lowest brackets of CIPS scores reveals some interesting relationships. Equal numbers of participants $(\mathrm{n}=16)$ had CIPS scores classified as Few Impostor Characteristics (scoring 40 points or less, henceforth termed "low CIPS") and Intense IP Experiences (scoring more than 80 points, henceforth termed "high CIPS"). For context, the two groups did differ somewhat in experience levels (see figure 9). While 68.8 percent of the low-CIPS group had more than 10 years of experience in libraries generally, 31.3 percent had more than 10 years of experience in scholarly communications specifically. Zero members of the low-CIPS group had two or fewer years in libraries, and only 6.3 percent had two or fewer years in scholarly communications. In contrast, in the high-CIPS group, 31.3 percent had more than 10 years of experience in libraries and zero members had more than 10 years in scholarly communications; 18.8 percent had two or fewer years in libraries, and 31.2 percent had two or fewer years in scholarly communications. However, the high-CIPS group also contained

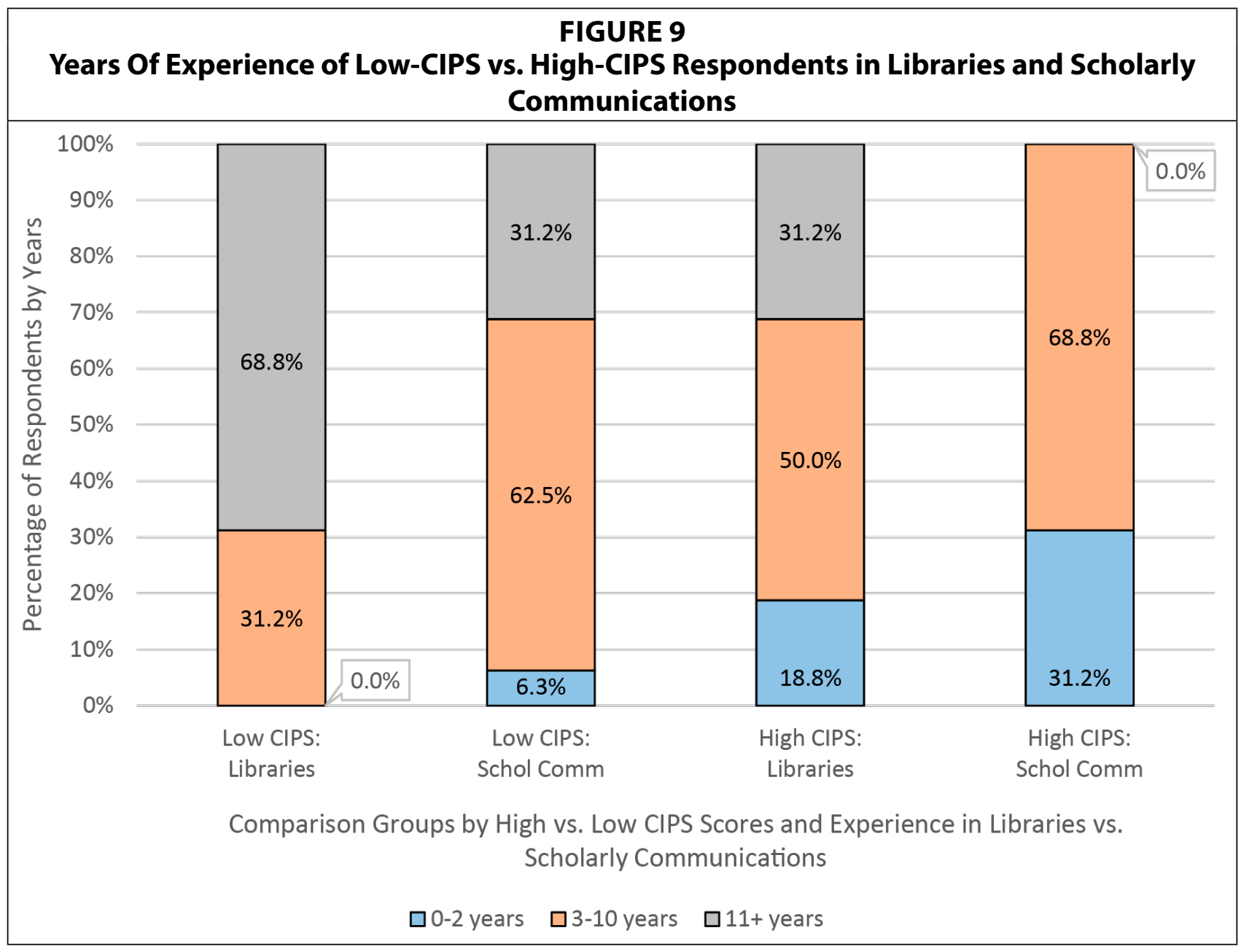


a significant number of midcareer individuals: 50.0 percent had between 3 and 10 years of experience in libraries, and 68.8 percent had between 3 and 10 years of experience in scholarly communications.

When asked to rate their confidence in key competencies, the difference between the low-CIPS and high-CIPS groups was significant. (The supplemental materials include graphs for all key areas, if not presented here: https://shsu-ir.tdl.org/handle/20.500.11875/2866). For example, in the area of Institutional Repository Management, whereas 50.0 percent of lowCIPS participants felt a great deal of confidence (5 on the Likert scale) in their Knowledge of and ability to apply publisher policies on archiving, only 18.8 percent of high-CIPS respondents felt a great deal of confidence in this area (see figure 10). While even low-CIPS individuals seemed less confident in their Knowledge of and ability to apply metadata schema, with only 18.8 percent reporting a great deal of confidence, not a single high-CIPS individual rated their confidence on this competency at a 5 .

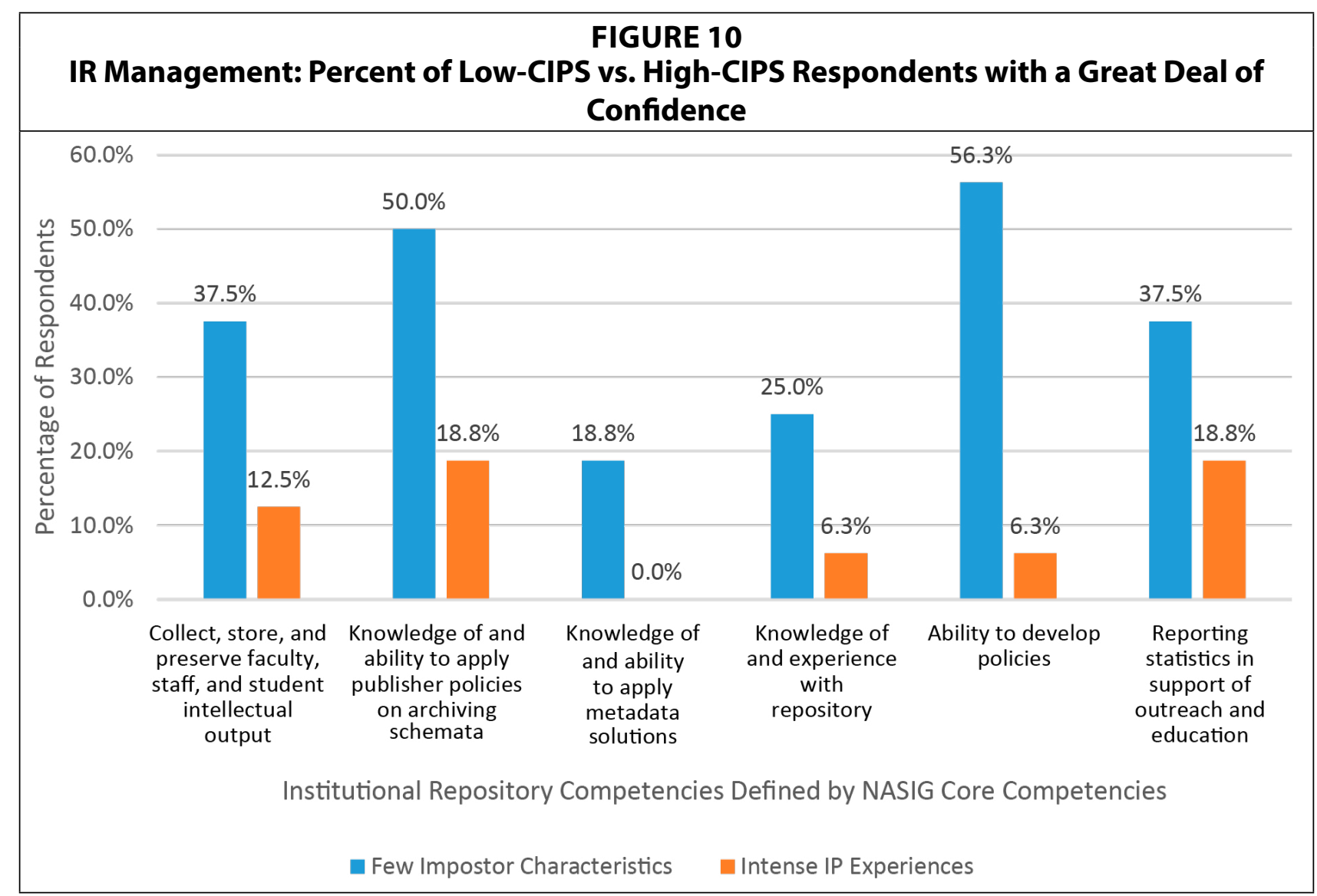

The negative correlation between CIPS and confidence level held true in the areas of Publishing and Copyright, as well as in the Key Strengths defined by NASIG. For example, zero high-CIPS participants reported a great deal of confidence in five of the seven competencies in the Publishing area, and the only two competencies with any such ratings were vastly lower compared to low-CIPS individuals: 12.5 percent versus 56.3 percent in Knowledge of and experience with the full life cycle of publishing, and 6.3 percent versus 25.0 percent in Collect and disseminate assessment metrics. 
Competencies in Copyright, too, saw a stark difference in confidence between lowCIPS and high-CIPS participants. For example, 68.8 percent of low-CIPS individuals felt a great deal of confidence concerning Campus copyright policies, compared to 12.5 percent of high-CIPS individuals. An equivalent 68.8 percent of low-CIPS individuals felt a great deal of confidence in Handling permission requests, compared to 25.0 percent of high-CIPS respondents.

However, this pattern saw a reversal in the area of Research Data Management (RDM). In these competencies, high-CIPS respondents were equally likely or more likely than lowCIPS respondents to feel a great deal of confidence in their skills. For example, 18.8 percent of high-CIPS individuals reported a great deal of confidence in Knowledge of text and data mining, whereas zero low-CIPS individuals reported the same confidence (see figure 11). However, it is also worth noting that confidence in both groups was much lower in this area's competencies across the board, with no competency surpassing 18.8 percent reporting a great deal of confidence.

\begin{tabular}{|c|c|c|c|c|}
\hline Research Data Management: Percent of Low-CIPS vs. High-CIPS Respondents with a Great \\
Deal of Confidence
\end{tabular}

In addition to competencies, individuals with lower incidence of impostor phenomenon also demonstrated greater confidence in their Key Strengths, compared to individuals with intense impostor experiences. While 81.3 percent of low-CIPS individuals reported a great deal of confidence in the Personable trait, only 43.8 percent of high-CIPS individuals shared that confidence (see figure 12). The lowest confidence for low-CIPS individuals occurred for the strength of Generalist, 43.8 percent, compared to just 12.5 percent among high-CIPS individuals. 


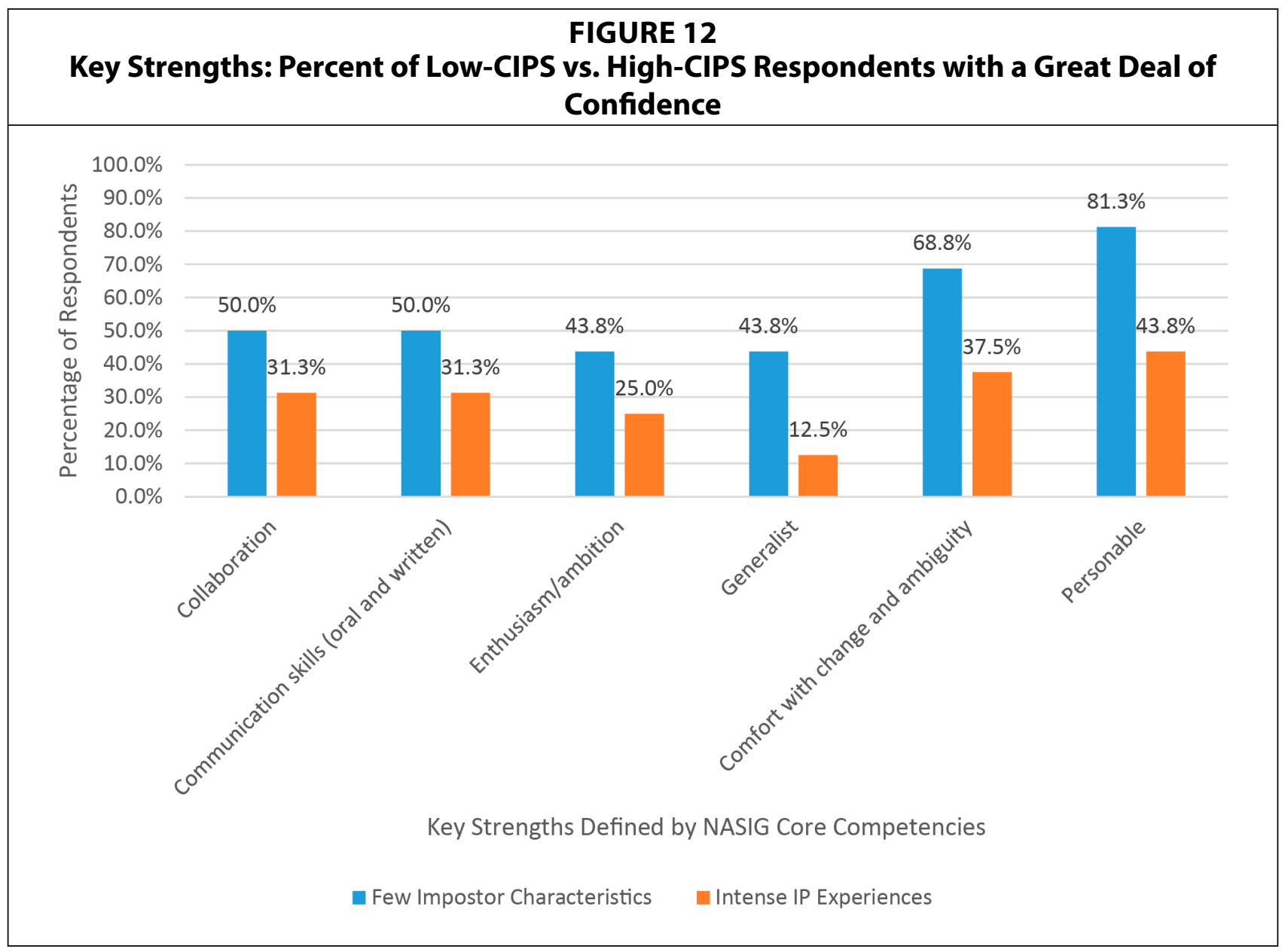

\section{Discussion}

A direct comparison of these results with the findings of previous studies by Clark, Vardeman, and Barba and Barr-Walker, Bass, Werner, and Kellermeyer is not possible, since their studies employed the Harvey Impostor Phenomenon Scale (HIPS) rather than the Clance Impostor Phenomenon Scale (CIPS). ${ }^{29}$ For example, Clark, Vardeman, and Barba reported that one in eight college librarians reported "above average" IP scores, based on the researchers' chosen benchmark of a score of 42 . However, we cannot clearly crosswalk a 42 on the Harvey scale to a score on the Clance scale. That having been said, if we consider Moderate IP Experiences to be the "average" zone on the Clance scale, then 52.3 percent of scholarly communications librarians reported scores above that average, in the zones of Frequent or Intense IP experience. That would indicate that the frequency of IP among scholarly communications librarians is closer to one in two-much higher than among college librarians more broadly, and higher even than what Barr-Walker, Bass, Werner, and Kellermeyer reported among health sciences librarians. If, instead, we assumed a benchmark score of 50-halfway up the Clance scale, similar the benchmark on the Harvey scale used by Clark et al. - then the picture becomes even bleaker, with 3 in 4, or 75 percent, of librarians reporting above-average feelings of impostorism.

What factors seem to affect this greater rate of impostor phenomenon among librarians specializing in scholarly communications? This study validates Clark's 2014 findings about academic librarians more broadly, that factors such as gender identity, race, and employment classification (in this case, tenured, tenure-track, and nontenure-track) are not significant factors in increasing IP. Additionally, although the researcher had anticipated a possible differ- 
ence between participants holding or lacking the MLS or equivalent professional degree, this also lacked any noteworthy effect on IP scores - however, since non-MLS personnel made up fewer than 7 percent of respondents, this study may not represent the most conclusive finding on the impact of the degree on IP. Scores were consistent between librarians at public and private institutions and across Carnegie classifications-so librarians supporting scholarly communications at R1 research institutions are no more or less likely to feel like impostors than librarians at master's or baccalaureate institutions. Taken together, these findings are encouraging on one level: librarians are not inherently disadvantaged by personal traits such as race or gender, nor by characteristics of employment such as institutional size.

On the other hand, years of experience in libraries did have a significant effect on the IP scores of scholarly communications librarians. This also validates Clark's 2014 findings about college librarians, that younger and less experienced individuals experienced more IP. This suggests that time and experience are some of the best means to resolve intense feelings of IP. The relationship between these variables and CIPS scores is further reinforced by participants' responses regarding confidence factors - insufficient time to focus on a particular competency and insufficient experience in applying knowledge accounted for the most significant areas of lacking confidence, and these factors boil down to time and experience.

Curiously, the number of years spent working in scholarly communications specifically was not significantly correlated to CIPS scores; a librarian does not necessarily feel more like an impostor when they are new to the specialization if they have accumulated enough experience in the broader profession itself. This may have implications regarding the transferability of general librarianship skills to scholarly communications duties, or it may simply reflect an increase in general self-confidence as any new skills are developed over time in the profession. More research may be warranted on how the skills of generalist librarianship or past specializations impact the experience of impostor phenomenon when first entering a new specialization.

While waiting for time and experience to accrue, academic librarians working in scholarly communications may also be able to take proactive steps to help alleviate their feelings of IP. The negative correlation between CIPS score and hours of continuing education suggests that an individual is unlikely to go amiss by taking advantage of more training and development. This is further supported by the third-highest rated factor affecting confidence, Lack of Training Completed, and this also fits with recommendations found in existing literature; for instance, Rakestraw explains: "Individuals who suffer from Imposter Syndrome often mistake being inexperienced with being unqualified... Imposter victims can take control of their inexperience by educating themselves in their professions." 30

However, librarians must also be cautious of allowing professional development to become a crutch or a barrier to skills application. Literature has noted that overpreparing is a common coping mechanism for those suffering from IP. ${ }^{31}$ If impostor phenomenon is stemming, as Rakestraw asserts, from misidentifying a lack of experience as a lack of qualification, then even significant education, if absent of skills application, may not convince a would-be impostor that their qualification level has changed. This may lead to overpreparing in the form of overtraining: that is, pursuing excessive quantities of professional development. In extreme cases, this may become a method of procrastinating and putting off action, which the impostor fears could result in failure. As Ackerman \& Gross note, "fear is an emotion that can produce a paralyzing effect," and Urwin further states that "Some individuals experiencing IP feel that tasks facing them are insurmountable and so delay starting, as they do not believe they can finish." 32 
This may be further tied up with the complex relationship between procrastination and perfectionism. For example, Onwuegbuzie (2000) observes that "overall academic procrastination appears to be related significantly to socially prescribed perfectionism," and "one possible explanation of the finding is that perfectionism leads to academic procrastination"; Sirois further clarifies that "trait procrastination and perfectionistic concerns may be characterised by similar negative self-evaluation tendencies that interfere with effective self-regulation and goal achievement." ${ }^{33}$ Burka sums it up concisely with one of the statements in her Procrastinator's Code: "There is a right answer, and I'll wait until I find it." 34

To maximize the benefits of professional development and minimize the risks of procrastinating via overpreparing or overtraining, further exploration may be warranted regarding the exact nature of continuing education opportunities within scholarly communications. The ability to define and understand complex concepts such as copyright, licensing, and research metrics may not immediately translate into the ability to apply these concepts in context; more hands-on training opportunities may be needed to advance genuine confidence in applying new concepts and skills. This is at least partially supported by the fourth- and fifth-highest rated factors affecting confidence, Lack of Practice and Demand, and Lack of Hands-on Training; if one has not yet received sufficient user demand to accumulate practice, one might benefit by gaining that practice via hands-on training instead.

In terms of other correlations, the negative correlation between CIPS scores and number of research publications suggests another logical way that librarians can increase their confidence in counseling faculty on the scholarly communications process. Librarians can gain first-hand experience with the entire scholarly cycle by conducting their own research, identifying and evaluating journals, negotiating their author rights, publishing their own article, promoting their publication, and gathering their own post-publication altmetrics and citations. This increased experience could reasonably be expected to boost a librarian's confidence that they understand and can practice what they are teaching to faculty.

Previous literature has recommended mentoring as one critical approach to help combat the experience of impostor phenomenon in librarianship. ${ }^{35}$ The current study's findings do not dispute that, but they do add potential nuance: there is an opportunity to encourage mentorship in the research and publication process specifically. Academic librarians more experienced in publishing can and should invite less experienced peers to collaborate and guide them through the process. This could potentially have a dual positive effect on impostor phenomenon by simultaneously providing both professional mentorship and first-hand experience in the scholarly communications process.

On another note, one must contemplate the significance of the leading reason for participants' lack in confidence: Too Many Responsibilities. One survey participant commented, "The NASIG competencies are ridiculously broad. No one can maintain top skills in all of the areas. Even maintaining top expertise in one of the areas is difficult in the faster-evolving areas." Indeed, we see that some large or strategically oriented libraries are able to employ teams of librarians to share the responsibilities of scholarly communication; in still other libraries, the primary librarians are supported by the secondary efforts of subject liaison librarians.

However, a number of academic libraries still have only one librarian, or perhaps two, bearing the vast majority of responsibility in this specialized area-this became anecdotally apparent when the author surveyed library directories, job titles, and LibGuides for survey recruitment, and the field might benefit from research into better understanding the weight 
of responsibilities placed on lone librarians supporting scholarly communications. Library directors should consider how the sheer scope of a scholarly communications librarian's responsibilities may impact the manifestation of impostor phenomenon and a librarian's lack of confidence in key skills areas. Even when an individual feels motivated to tackle all these duties, the urge to master them all can sometimes inhibit forward progress: as Burka observes of the would-be Renaissance Man, "the need to be well-versed in everything often prevents from pursuing anything." ${ }^{36}$ Creative ways to spread out responsibilities, train "assistant" librarians to provide backup in key areas such as copyright, or develop team-based support structures may help to alleviate the burden of expectations placed on a single individual and thus decrease the issues that may arise from an excessive experience of IP.

Identifying the negative correlation between CIPS scores and confidence in core competencies is illuminating. To some extent, this may still be the result of different levels of experience, since the low-CIPS group did tend to have more years of experience than the high-CIPS group in both libraries generally and in scholarly communications. However, both the low-CIPS and high-CIPS groups contained a sizable number of midcareer librarians with 3-10 years of experience, implying that other personal factors may be in play besides simple years of experience in the field. Even with comparable years of experience, some librarians experience less impostor phenomenon, negatively correlated with greater degrees of confidence in their skills, while other librarians experience more impostor phenomenon, negatively correlated to lower confidence in skills.

This relationship suggests that librarians experiencing IP are unlikely to be objective judges of their own competencies. Their own biased judgment of themselves may negatively impact these librarians' productivity - for example, recalling the earlier discussion of procrastination, if they are constantly trying to compensate for a perceived lack of competence by engaging in ever more professional development. Their subjective lack of confidence may also hinder their pursuit of opportunities such as jobs, grants, or projects for which they may feel they are lacking sufficient mastery of necessary competencies. The development of objective, empirical competency tests in scholarly communications skills areas could help these experts to more accurately assess their own competency levels. Not only could this remove obstacles standing in the way of substantive professional pursuits, but receiving unbiased evidence of one's own capacity would potentially help to reduce the experience of IP itself.

\section{Limitations and Further Research}

This study was geographically limited to the United States. Given the extensive international diversity in access to information, open-access mandates, and open-access philosophy more broadly, the author judged that analysis of comparing confidence levels in approaching these scholarly communications topics would be too complex across international borders. Further research could similarly survey librarians in other countries to provide comparative findings.

Because this study is based on voluntary survey responses, the participant pool may suffer from self-selection bias. Invitees who read the survey topic and related to the experience of impostor phenomenon may have been more likely to respond than those invitees who had not experienced or were not strongly affected by feelings of IP. Conversely, some invitees who felt strong emotions about their IP experiences may have avoided the study or withdrawn before completing if the questions caused discomfort. The participant pool may also have been small, but it is difficult to judge without having evidence to state the total population of scholarly communications librarians in the United States. 
Additionally, the structure of the survey instrument itself may have presented some limitations. Participants were first asked to indicate areas of lower confidence in scholarly communications competencies, then follow-up questions asked them to consider factors affecting their confidence level. However, because the survey did not include a button to navigate back to previous pages, participants were limited in their ability to refer back to the specific competencies and confidence levels they had previously marked. This may have affected the precision with which respondents answered the follow-up questions about contributing factors.

Another limitation of the study is that the NASIG Core Competencies did not explicitly include Open Educational Resources (OER), a topic that nevertheless often falls under the broad umbrella of scholarly communications work in academic libraries. Integrating additional competencies into the survey might have contributed additional insight into librarian confidence regarding OER competencies.

Another opportunity for future research might be to longitudinally survey a cohort of librarians about IP and confidence as they enter the scholarly communications specialization and again at various points over the next several years of their careers. By limiting the focus to the same participants over time, certain variables between individuals could be controlled, while the impact of interventions such as continuing education, mentoring, hands-on experience, and so forth could be more fully evaluated. However, the logistics of identifying and enrolling such a population could prove rather challenging.

Additionally, because the factor of Too Many Responsibilities significantly affected confidence, further research could investigate whether employer expectations on average are too high for librarians in this specialty. A future project could analyze library job descriptions in scholarly communications, comparing listed duties to the NASIG Core Competencies to determine how comprehensively professionals are expected to support the specialty.

\section{Conclusions}

Academic librarians specializing in scholarly communications work seem to experience intense impostor phenomenon at a higher rate than academic librarians more broadly. Their confidence in their skills varies across an array of professionally defined competencies, but, across the board, the factors having the greatest negative impact on confidence are a surplus of professional responsibilities and a lack of applied practice. With the insight provided by this study, the LIS profession can better understand the experience of these specialists, better support them in developing greater job competence and confidence, and perhaps direct more energy to developing novel interventions such as more hands-on applied training opportunities.

\section{Acknowledgments}

The author would like to acknowledge Micheline R. Anderson for her guidance on statistical testing.

\section{Notes}

1. Robin Chin Roemer and Rachel Borchardt, "New Grads, Meet New Metrics: Why Early Career Librarians Should Care about Altmetrics \& Research Impact," In the Library with the Lead Pipe (12 August 2015): under "Obstacles \& Opportunities," www.inthelibrarywiththeleadpipe.org/2015/new-grads-meet-new-metrics-whyearly-career-librarians-should-care-about-altmetrics-research-impact/ [accessed 19 December 2019].

2. Pauline Rose Clance and Suzanne Ament Imes, "The Impostor Phenomenon in High Achieving Women: Dynamics and Therapeutic Intervention," Psychotherapy: Theory, Research \& Practice 15, no. 3 (Fall 1978): 241, 
https://doi.org/10.1037/h0086006.

3. Clance and Imes, "The Imposter Phenomenon in High Achieving Women."

4. Manfred F.R. Kets de Vries, "The Dangers of Feeling like a Fake," Harvard Business Review 83, no. 9 (2005): 111.

5. Holly M. Hutchins and Hilary Rainbolt, “What Triggers Imposter Phenomenon among Academic Faculty? A Critical Incident Study Exploring Antecedents, Coping, and Development Opportunities," Human Resource Development International 20, no. 3 (June 2017): 194-214, https://doi.org/10.1080/13678868.2016.1248205.

6. Anna Parkman, "The Imposter Phenomenon in Higher Education: Incidence and Impact," Journal of Higher Education Theory \& Practice 16, no. 1 (March 2016): 51-60.

7. Holly M. Hutchins, Lisa M. Penney, and Lisa W. Sublett, “What Imposters Risk at Work: Exploring Imposter Phenomenon, Stress Coping, and Job Outcomes," Human Resource Development Quarterly 29, no. 1 (Spring 2018): 31-48, https://doi.org/10.1002/hrdq.21304.

8. See, for example: Ashley E. Faulkner, "Reflections on the Impostor Phenomenon as a Newly Qualified Academic Librarian," New Review of Academic Librarianship 21, no. 3 (2015): 265-68, https://doi.org/10.1080/1361 4533.2015.1070185; Wendy Girven Pothier, Heather Howard, and Paul Campbell, "Pathways to Becoming an Academic Subject Specialist: Insights from Three Librarians," Partnership: The Canadian Journal of Library $\mathcal{E}$ Information Practice E Research 14, no. 1 (2019): 1-9, https://doi.org/10.21083/partnership.v14i1.5172.

9. See, for example: Rachel Singer Gordon, "Overcoming the Systems Librarian Imposter Syndrome," LIBRES: Library \& Information Science Research Electronic Journal 13, no. 2 (2003), available online at https://www. libres-ejournal.info/905/ [accessed 19 December 2019]; Sajni Lacey and Melanie Parlette-Stewart, "Jumping into the Deep: Imposter Syndrome, Defining Success, and the New Librarian," Partnership: The Canadian Journal of Library $\mathcal{E}$ Information Practice $\mathcal{E}$ Research 12, no. 1 (January 2017): 1-15, https://doi.org/10.21083/partnership. v12i1.3979; Bridget Farrell et al., "Addressing Psychosocial Factors with Library Mentoring," portal: Libraries $\mathcal{E}$ the Academy 17, no. 1 (January 2017): 51-69; Lacy Rakestraw, "How to Stop Feeling Like a Phony in Your Library: Recognizing the Causes of the Imposter Syndrome, and How to Put a Stop to the Cycle," Law Library Journal 109, no. 3 (Summer 2017): 465-77.

10. Farrell et al., "Addressing Psychosocial Factors with Library Mentoring"; Rakestraw, "How to Stop Feeling Like a Phony in Your Library."

11. Jill Barr-Walker et al., "Coping with Impostor Feelings: Evidence Based Recommendations from a Mixed Methods Study," Evidence Based Library and Information Practice 15, no. 2 (June 2020): 24-41, https://doi.org/10.18438/ eblip29706.

12. Melanie Clark, Kimberly Vardeman, and Shelley Barba, "Perceived Inadequacy: A Study of the Imposter Phenomenon among College and Research Librarians," College \& Research Libraries 75, no. 3 (2014): 255-71, https:// doi.org/10.5860/crl12-423.

13. Jessica Martinez and Meredith Forrey, “Overcoming Imposter Syndrome: The Adventures of Two New Instruction Librarians," Reference Services Review 47, no. 3 (2019): 331-42.

14. Dominique Bortmas, "Destroying Impostor Phenomenon in Code4Lib and Ourselves," Code4Lib Conference, March 7, 2017, https://2017.code4lib.org/talks/Destroying-Impostor-Phenomenon-in-Code4Lib-andOurselves.

15. Jill Barr-Walker et al., "Measuring Impostor Phenomenon among Health Sciences Librarians," Journal of the Medical Library Association 107, no. 3 (2019): 323-32, https://doi.org/10.5195/jmla.2019.644.

16. Core Competencies of Scholarly Communication Librarians, NASIG, https://www.nasig.org/CompetenciesScholarly-Communication.

17. Scholarly Communications Toolkit, Association of College and Research Libraries, https://acrl.libguides. com/scholcomm/toolkit.

18. Competency Model for Bibliometric Work, The Bibliomagician, https:/thebibliomagician.wordpress.com/ competencies/; Librarians' Competencies Profile for Research Data Management, Joint Task Force on Librarians' Competencies in Support of EResearch and Scholarly Communication, https://www.coar-repositories.org/files/ Competencies-for-RDM_June-2016.pdf.

19. Librarians' Competencies Profile for Scholarly Communication and Open Access, Joint Task Force on Librarians' Competencies in Support of EResearch and Scholarly Communication, https://www.coar-repositories. org/files/Competencies-for-ScholComm-and-OA_June-2016.pdf.

20. Scholarly Communications Competencies, Jisc, https://docs.google.com/document/d/1nNlGz4iugVHIYV Xn97_2yWED2KxmbukFNJx9fki3XUc/edit.

21. Pauline Rose Clance, "Clance IP Scale," in The Impostor Phenomenon: When Success Makes You Feel Like a Fake (Toronto, ON: Bantam Books, 1985): 20-22, http://paulineroseclance.com/impostor_phenomenon.html [accessed 20 December 2019]. 
22. J.C. Harvey, The Impostor Phenomenon and Achievement: A Failure to Internalise Success (unpublished doctoral dissertation, Temple University, 1981); Clance, "Clance IP Scale"; J. Kolligian and R J. Sternberg, "Perceived Fraudulence in Young Adults: Is There an 'Impostor Syndrome'?" Journal of Personality Assessment 56 (1991): 308-26, https://doi.org/10.1207/s15327752jpa5602_10; M.R. Leary, Imposterism Scale, https://doi.org/10.13072/midss.599; Rieko Fujie, "Development of the State Impostor Phenomenon Scale," Japanese Psychological Research 52, no. 1 (2010): $1-11$.

23. Karina K.L. Mak, Sabina Kleitman, and Maree J. Abbott, "Impostor Phenomenon Measurement Scales: A Systematic Review," Frontiers in Psychology 10 (2019), https://doi.org/10.3389/fpsyg.2019.00671; Chan M. Hellman and Tonia D. Caselman, "A Psychometric Evaluation of the Harvey Imposter Phenomenon Scale," Journal of Personality Assessment 83, no. 2 (2004): 161-66; Sabine M. Chrisman et al., "Validation of the Clance Impostor Phenomenon Scale," Journal of Personality Assessment 65, no. 3 (1995): 456-67; Sarah W. Holmes et al., "Measuring the Impostor Phenomenon: A Comparison of Clance's IP Scale and Harvey's I-P Scale," Journal of Personality Assessment 60, no. 1 (1993): 48-59, https://doi.org/10.1207/s15327752jpa6001_3; Patrick W. Edwards et al., "A Validation Study of the Harvey Impostor Phenomenon Scale," Psychotherapy: Theory, Research, Practice, Training 24, no. 2 (1987): 256-59, https://doi.org/10.1037/h0085712.

24. Impostor Syndrome, APA Dictionary of Psychology, https://dictionary.apa.org/impostor-phenomenon [accessed 20 December 2019].

25. The Carnegie Classification of Institutions of Higher Education, http://carnegieclassifications.iu.edu/ [accessed 20 December 2019].

26. Examples of key terms sought in job titles included not only scholarly communication(s), but also research data (management), (research / impact) metrics, open (access, knowledge, education, etc.), copyright, publishing, and related variants. Because terminology in individual and department titles varies so widely among institutions, this searching was done by manual critical examination of the entire library personnel directory, as well as examining authorship of relevant library research guides.

27. Listservs contacted were as follows: ACRL Schol-Com listserv (scholcomm@lists.ala.org), ACRL Research and Scholarly Environment Committee (ReSEC, acrl-scholcommcmte@lists.ala.org), ACRL Research Assessment and Metrics Interest Group (ResMetIG, resmetig@lists.ala.org), ACRL Digital Scholarship Section (DSS) Research Data Management Discussion Group (dss-rdm_dg@lists.ala.org), ACRL Numeric and Geospatial Data Services in Academic Libraries Interest Group (dss-ngds_dg@lists.ala.org).

28. Pauline Rose Clance, Clance Impostor Phenomenon Scale and scoring instructions (CIPS), http://paulineroseclance.com/impostor_phenomenon.html.

29. Clark, Vardeman, and Barba, "Perceived Inadequacy"; Barr-Walker et al., "Measuring Impostor Phenomenon among Health Sciences Librarians."

30. Rakestraw, "How to Stop Feeling Like a Phony in Your Library," 473 (italics in the original).

31. See, for instance, Clance, The Impostor Phenomenon; Hutchins, Penney, and Sublett, "What Imposters Risk at Work"; Rakestraw, "How to Stop Feeling Like a Phony in Your Library."

32. David S. Ackerman and Barbara L. Gross, “I Can Start That JME Manuscript Next Week, Can't I? The Task Characteristics behind Why Faculty Procrastinate," Journal of Marketing Education 29, no. 2 (August 2007): 97; Jessica Urwin, "Imposter Phenomena and Experience Levels in Social Work: An Initial Investigation," British Journal of Social Work 48, no. 5 (July 2018): 1435, https://doi.org/10.1093/bjsw/bcx109. Clance, The Impostor Phenomenon, also discussed procrastination as an approach common in individuals experiencing IP.

33. Anthony J. Onwuegbuzie, "Academic Procrastinators and Perfectionistic Tendencies among Graduate Students," Journal of Social Behavior \& Personality 15, no. 5 (December 2, 2000): 108; Fuschia M. Sirois et al., "A Meta-Analytic and Conceptual Update on the Associations Between Procrastination and Multidimensional Perfectionism," European Journal of Personality 31, no. 2 (March 2017): 155. For more, see also Yu Xie, Jiyu Yang, and Faxiang Chen, "Procrastination and Multidimensional Perfectionism: A Meta-Analysis of Main, Mediating, and Moderating Effects," Social Behavior and Personality: An International Journal, no. 3 (2018): 395. 16.

34. Jane B. Burka, Procrastination: Why You Do It, What to Do About It (Reading, MA: Addison-Wesley, 1983),

35. See, for instance, Farrell et al., "Addressing Psychosocial Factors with Library Mentoring"; Rakestraw, "How to Stop Feeling Like a Phony in Your Library"; Barr-Walker et al., "Coping with Impostor Feelings." In academia but outside of strictly libraries, see among others, Parkman, "The Imposter Phenomenon in Higher Education"; T. Elon Dancy II and M. Christopher Brown II, "The Mentoring and Induction of Educators of Color: Addressing the Impostor Syndrome in Academe," Journal of School Leadership 21, no. 4 (July 2011): 607-34; and Wendy L. Sims and Jane W. Cassidy, "Impostor Phenomenon Responses of Early Career Music Education Faculty," Journal of Research in Music Education 67, no. 1 (April 2019): 45-61.

36. Burka, Procrastination, 110 (italics in the original). 